\title{
"Levan versus fructooligosaccharide synthesis using the levansucrase from Zymomonas mobilis: effect of reaction conditions"
}

Paloma Santos-Moriano ${ }^{\mathrm{a}}$, Lucia Fernandez-Arrojo ${ }^{\mathrm{a}}$, Ana Poveda ${ }^{\mathrm{b}}$, Jesus Jimenez-Barbero $^{\mathrm{c}}$, Antonio O. Ballesteros ${ }^{\mathrm{a}}$ and Francisco J. Plou ${ }^{\mathrm{a}, *}$

${ }^{a}$ Instituto de Catálisis y Petroleoquímica, CSIC, 28049 Madrid, Spain

${ }^{b}$ Servicio Interdepartamental de Investigación, UAM, 28049 Madrid, Spain ${ }^{c}$ Centro de Investigaciones Biológicas, CSIC, 28040 Madrid, Spain

Published in:

Journal of Molecular Catalysis B: Enzymatic 119, 18-25 (2015).

http://dx.doi.org/10.1016/j.molcatb.2015.05.011 


\title{
Levan versus fructooligosaccharide synthesis using the levansucrase from Zymomonas mobilis: effect of reaction conditions
}

\author{
Paloma Santos-Moriano ${ }^{\mathrm{a}}$, Lucia Fernandez-Arrojo ${ }^{\mathrm{a}}$, Ana Poveda ${ }^{\mathrm{b}}$, Jesus \\ Jimenez-Barbero $^{\mathrm{c}}$, Antonio O. Ballesteros ${ }^{\mathrm{a}}$ and Francisco J. Plou ${ }^{\mathrm{a}, *}$
}

\author{
a Instituto de Catálisis y Petroleoquímica, CSIC, 28049 Madrid, Spain \\ ${ }^{\mathrm{b}}$ Servicio Interdepartamental de Investigación, UAM, 28049 Madrid, Spain \\ ${ }^{c}$ Centro de Investigaciones Biológicas, CSIC, 28040 Madrid, Spain \\ * Corresponding author: Francisco J. Plou, Departamento de Biocatálisis, Instituto de \\ Catálisis y Petroleoquímica, CSIC, Cantoblanco, Marie Curie 2, 28049 Madrid, Spain. \\ Fax: +34-91-5854760. E-mail: fplou@ icp.csic.es. http://www.franciscoploulab.eu/
}

\begin{abstract}
This work addresses the effect of sucrose concentration and temperature on the three activities displayed by the levansucrase from Zymomonas mobilis: formation of levan (polymerization), production of short-chain fructooligosaccharides (FOS), and sucrose hydrolysis. Of the conditions tested, levan formation reached the highest value at $4^{\circ} \mathrm{C}$ and $100 \mathrm{~g} / \mathrm{L}$ sucrose. The increase of temperature $\left(40^{\circ} \mathrm{C}\right)$ and sucrose concentration $(600 \mathrm{~g} / \mathrm{L})$ caused a significant decrease of the levan concentration and a higher production of FOS. However, an increase of the temperature also caused an enhancement of the undesired hydrolytic activity. Several inulin-type FOS (1-kestose, nystose, ${ }^{1}$ F-fructosylnystose), neoFOS (blastose, neokestose, neonystose) and levan-type FOS (6-kestose, 6,6-nystose) were synthesized by levansucrase. The latter compound was purified and characterized by mass spectrometry and 2D NMR. Using $600 \mathrm{~g} / \mathrm{L}$ sucrose at $40^{\circ} \mathrm{C}$, the maximum yield of FOS was reached at $85 \%$ sucrose conversion; at this point, the reaction mixture contained (in weight basis) $31 \%$ glucose, $14 \%$ fructose, $15 \%$ sucrose and $40 \%$ FOS (including a small contribution of levan).
\end{abstract}

Key words: levan, transfructosylation, prebiotics, fructooligosaccharides, GH68 family, biopolymers.

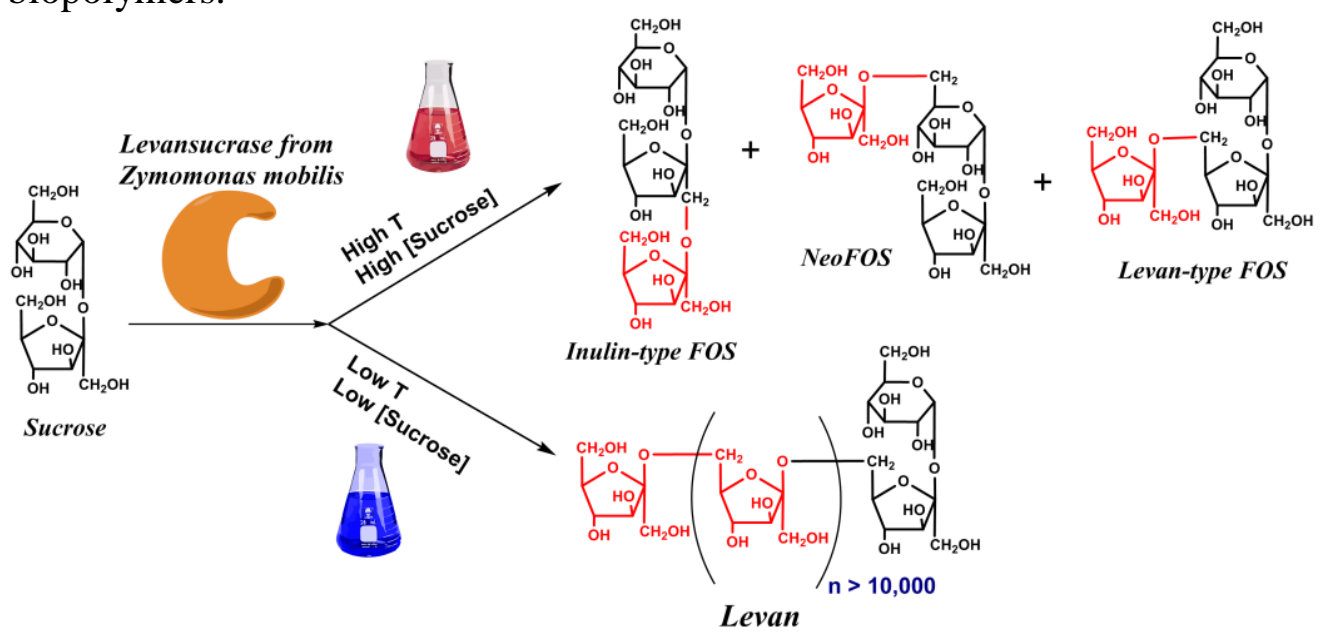




\section{INTRODUCTION}

Levansucrases (EC 2.4.1.10) are bacterial extracellular enzymes that belong to the glycoside hydrolase family GH68 [1]. They are also known as $\beta(2 \rightarrow 6)$ fructosyltransferases because they catalyze the formation of levan, a $\beta(2 \rightarrow 6)$-linked fructose homopolymer with some $\beta(2 \rightarrow 1)$-linked branching points [2]. Due to its unique properties, levan has potential applications in the food, cosmetic, and pharmaceutical industries, as well as in medicine [3]. In the food industry, levan can be used as an emulsifier, flavour modifier, stabilizer, thickener, antibacterial and encapsulation agent [4]. It can also act as a low caloric and non-cariogenic sugar substitute with prebiotic effect $[5,6]$.

Levan is found in microbial cultures of Bacillus subtilis [7], Zymomonas mobilis [8], Microbacterium laevaniformans [9], Bacillus amyloliquefaciens [10], Bacillus methylotrophicus [11] or Halomonas sp. [12]. It has been also produced by alginateentrapped cells of Z. mobilis [13] or B. subtilis [14]. However, cell production is limited by the requirements of the microorganism in order to produce biomass, and the growing conditions may not be the same as the optimal conditions for levan synthesis. For that reason, free or immobilized levansucrases are preferred for such bioprocesses. For example, levansucrase has been immobilized on chitin beads [15] or on the surface of magnetite [16] for the production of levan.

Apart from levan formation, levansucrases also produce fructooligosaccharides (FOS) of formula $\mathrm{GF}_{\mathrm{n}}$, (with $n$ ranging from 1 to 10) [17], which are formed by sequential transfructosylation of a fructosyl moiety to a molecule of sucrose. FOS show a low values of caloric intake ( $2 \mathrm{kcal} / \mathrm{g}$ ) and glycemic index, and are used as food ingredients due to their prebiotic properties favouring the development of bifidobacteria and lactobacillus, as well as other side effects such as a reduced risk of suffering colon cancer, an improved gut absorption of $\mathrm{Ca}^{2+}$ and $\mathrm{Mg}^{2+}$, and a reduction of blood lipid levels [18]. The type of linkage between fructoses in the FOS synthesized by levansucrase is reported to be mainly of the $\beta(2 \rightarrow 6)$ type, thus yielding 6-kestose and other FOS of the ${ }^{6} \mathrm{~F}$-series [17]. However, the production of FOS of the ${ }^{1}$ F-series (e.g. 1-kestose) and ${ }^{6} \mathrm{G}$-series (e.g. neokestose) has also been reported for some levansucrases [9]. The hydrolytic activity of levansucrases gives rise to the formation of free fructose; this monosaccharide can also accept fructosyl units yielding levan oligomers (levanbiose, levantriose, etc.) [19].

Although both levan and FOS present interesting properties, it is desirable to control the selective production of one of these derivatives as they possess different physical and biological properties. Several reaction conditions, such as temperature and ethanol content, are known to influence levan or FOS production [20-22]. In order to elucidate the mechanisms that modulate the formation of short-chain FOS vs. levan, various structural and mutagenesis studies have been carried out [23,24]. Trying to overcome the problem of product selectivity, Tian et al. proposed the combination of levansucrase with an endoinulinase in a one-pot bi-enzymatic system [25,26].

In this work we have studied the effect of various experimental parameters on the levan $v s$. FOS production using a levansucrase from Zymomonas mobilis. The hydrolytic activity of the enzyme was also evaluated under the different conditions. The levan fraction was analyzed by size exclusion chromatography, and the main synthesized FOS were chemically characterized to get a complete profile of the synthetic reaction. 


\section{MATERIALS \& METHODS}

\subsection{Materials}

Levansucrase (LEV-Y) from Zymomonas mobilis was obtained as a powder preparation from Amano Enzyme Inc. (Nagoya, Japan). Sucrose, glucose and fructose were from Merck. 1-Kestose and nystose were from TCI Europe. ${ }^{1}$ F-Fructosylnystose was from Megazyme. Commercial levan from Zymomonas mobilis was from Sigma-Aldrich. 6Kestose, blastose, neokestose and neonystose were purified in the laboratory as previously described [27,28]. All reagents and chemicals were of analytical reagent grade.

\subsection{Characterization of the enzyme}

The activity of levansucrase was determined using $100 \mathrm{~g} / \mathrm{L}$ sucrose as substrate by the 3,5dinitrosalicylic acid (DNS) assay for reducing sugars adapted to 96-well plates [29]. One unit of activity (U) was defined as that corresponding to the release of one $\mu$ mol of reducing sugar per minute. Total protein concentration was determined based on the Bradford assay using Bio-Rad dye reagent. Molecular weight of the protein was estimated by loading the enzymatic preparation in a 10\% SDS polyacrylamide gel stained with Protoblue ${ }^{\mathrm{TM}}$ Safe (National Diagnosis) and comparing the size of the major band with standard protein markers (Novagen).

For the analysis of optimal $\mathrm{pH}$, the activity towards $100 \mathrm{~g} / \mathrm{L}$ sucrose was measured by the DNS assay at $40^{\circ} \mathrm{C}$ for $20 \mathrm{~min}$ in $50 \mathrm{mM}$ Britton \& Robinson (B\&R, acetate-phosphateborate) buffer [30] at different $\mathrm{pH}$ values (2.0-9.0). For the determination of optimal temperature, $50 \mu \mathrm{L}$ solutions containing both $5 \mathrm{U} / \mathrm{mL}$ levansucrase and $100 \mathrm{~g} / \mathrm{L}$ sucrose were incubated at different temperatures $\left(30-80^{\circ} \mathrm{C}\right)$ in $50 \mathrm{mM}$ sodium acetate buffer $(\mathrm{pH}$ 5.4) in a thermocycler (BioRad) using PCR microplates. The concentration of reducing sugars was measured by the DNS assay. All the experiments were performed in triplicate and the error was expressed as the standard deviation of the three measurements.

\subsection{Production of levan by levansucrase}

Production of levan by levansucrase was studied under different conditions and followed by size exclusion chromatography (SEC) using a ternary pump (Varian) coupled to a PolySep 4000 column (300 x $7.8 \mathrm{~mm})$ from Phenomenex (Terrace, CA) with an evaporative light scattering detector (ELSD 2000ES, Alltech). Mobile phase was $\mathrm{H}_{2} \mathrm{O}$ at $0.6 \mathrm{~mL} / \mathrm{min}$. ELSD conditions were set at $115^{\circ} \mathrm{C}$ and a nitrogen flow of $3.5 \mathrm{~L} / \mathrm{min}$. Reactions with $5 \mathrm{U} / \mathrm{mL}$ levansucrase were carried out in an orbital shaker (Vortemp) using 100 or $600 \mathrm{~g} / \mathrm{L}$ sucrose in $50 \mathrm{mM}$ acetate buffer $(\mathrm{pH} 5.0)$ at $4^{\circ} \mathrm{C}$ or $40^{\circ} \mathrm{C}$. Aliquots were taken at $0 \mathrm{~h}, 2 \mathrm{~h}, 24 \mathrm{~h}$ and $48 \mathrm{~h}$, inactivated with $0.4 \mathrm{M} \mathrm{Na}_{2} \mathrm{CO}_{3}$, filtered with $0.45 \mu \mathrm{m}$ nylon syringe filters (Análisis Vínicos, Tomelloso, Spain) and diluted 1:5 and 1:10 with $\mathrm{H}_{2} \mathrm{O}$ before SEC analysis. Molecular weight of the products was estimated by comparison with dextran standards (180-140,000 Da, Phenomenex).

\subsection{Production of fructooligosaccharides by levansucrase}

To a solution of $600 \mathrm{~g} / \mathrm{L}$ sucrose in $50 \mathrm{mM}$ sodium acetate buffer (pH 5.4) levansucrase $(5 \mathrm{U} / \mathrm{mL})$ was added and the mixture incubated at $40^{\circ} \mathrm{C}$ with gentle stirring. Aliquots were taken at different times, inactivated with $0.4 \mathrm{M} \mathrm{Na}_{2} \mathrm{CO}_{3}$, filtrated with $0.45 \mu \mathrm{m}$ nylon syringe filters and conveniently diluted before analysis. The identification of fructooligosaccharides was carried out by High Performance Anion-Exchange Chromatography with Pulsed Amperometric Detection (HPAEC-PAD) on a Dionex ICS3000 system consisting of an SP gradient pump, an electrochemical detector with a gold working electrode and $\mathrm{Ag} / \mathrm{AgCl}$ as reference electrode, and an autosampler 
(model AS-HV). All eluents were degassed by flushing with helium. Two different columns, CarboPack PA1 (4 x 250 mm) for small FOS and CarboPack PA200 (4 x 250 $\mathrm{mm}$ ) for higher oligosaccharides, were used. For the CarboPack PA1 column, initial mobile phase was $20 \mathrm{mM} \mathrm{NaOH}$ at $1 \mathrm{~mL} / \mathrm{min}$ and it was maintained for $13 \mathrm{~min}$. Then a gradient from 20 to $100 \mathrm{mM} \mathrm{NaOH}$ and from 0 to $40 \mathrm{mM}$ sodium acetate was performed in $7 \mathrm{~min}$. These conditions were kept for $10 \mathrm{~min}$ and then sodium acetate concentration was increased from 40 to $100 \mathrm{mM}$ in $5 \mathrm{~min}$ and maintained for $2 \mathrm{~min}$. For the CarboPack PA200 column, initial mobile phase was $100 \mathrm{mM} \mathrm{NaOH}$ at $0.5 \mathrm{~mL} / \mathrm{min}$. $\mathrm{NaOH}$ concentration was kept constant throughout the program. A sodium acetate gradient from 0 to $160 \mathrm{mM}$ was carried out in the first $15 \mathrm{~min}$ and from 160 to $320 \mathrm{mM}$ in the following 45 min. These conditions were kept for $35 \mathrm{~min}$. The quantification of the main products was performed using available standards. The identification of higher oligosaccharides was done by comparison with an inulin standard (Raftiline, Orafti, Belgium).

\subsection{Purification of oligosaccharides}

Unknown fructooligosaccharides were purified using semipreparative HPLC with a Delta 600 pump (Waters) and a Kromasil- $\mathrm{NH}_{2}$ column $(5 \mu \mathrm{m}, 10$ x $250 \mathrm{~cm}$, Analisis Vinicos). A three-way flow splitter (model Accurate, Dionex) and a refraction index detector (Waters, model 2410) equilibrated at $30^{\circ} \mathrm{C}$ were used. Acetonitrile/water 68:32 $(\mathrm{v} / \mathrm{v})$, degassed with helium, was used as mobile phase at $4.7 \mathrm{~mL} / \mathrm{min}$. The column temperature was kept constant at $30^{\circ} \mathrm{C}$. After collecting the different oligosaccharides, the mobile phase was eliminated by rotary evaporation in a R-210 rotavapor (Buchi). Isolated products were characterized by mass spectroscopy and NMR.

\subsection{Mass spectrometry.}

The molecular weight of the unknown carbohydrates was analyzed by MALDI-TOF mass spectrometry (Bruker, model Ultraflex III TOF/TOF) using 2,5-dihidroxybenzoic acid doped with sodium iodide as matrix, in positive reflector mode.

\subsection{Nuclear magnetic resonance (NMR).}

The structure of the purified carbohydrates was elucidated using a combination of ${ }^{1} \mathrm{H}$ and ${ }^{13} \mathrm{C}-\mathrm{NMR}$, employing $1 \mathrm{D}$ and 2D (COSY, NOESY, HSQC, HSQC-TOCSY. HMBC) techniques. The spectra of the sample (ca. $10 \mathrm{mM}$ ), dissolved in deuterated water, was recorded on a Bruker AVANCE DRX500 spectrometer equipped with a tuneable broadband $1 \mathrm{H} / \mathrm{X}$ probe with a gradient in the $\mathrm{Z}$ axis, at a temperature of $298 \mathrm{~K}$. Chemical shifts were expressed in $\mathrm{ppm}$ with respect to the $0 \mathrm{ppm}$ point of DSS, used as internal standard. All the experiments were run using standard sequences provided by Bruker. COSY and NOESY (500 ms mixing time) experiments were performed with 8 and 64 scans, respectively, with 384 increments in the indirect dimension and with 1024 points in the acquisition dimension. The spectral widths were $4 \mathrm{ppm}$ in both dimensions. The HSQC, HSQC-TOCSY (60 ms mixing time) and HMBC experiments were performed with 8,16 and 64 scans, respectively, with 384 increments in the indirect dimension and with 1024 points in the acquisition dimension. The spectral width was $70 \mathrm{ppm}(80 \mathrm{ppm}$ for the $\mathrm{HMBC})$ in the indirect dimension $\left({ }^{13} \mathrm{C}\right)$ and $3 \mathrm{ppm}$ in the acquisition one $\left({ }^{1} \mathrm{H}\right)$. All the $2 \mathrm{D}$ experiments were transformed to a 4096 x 4096 matrix in order to improve resolution and resolve the overlapping signals as much as possible. 


\section{RESULTS AND DISCUSSION}

\subsection{Levan vs. FOS formation by levansucrase}

Levansucrases display three different catalytic activities. First, they form levan by the transfer of the fructosyl moiety of sucrose to a growing polymer chain, releasing glucose as side product [31]. In addition, the fructosyl group can be also transferred to small carbohydrates acting as acceptors (e.g. glucose, sucrose) yielding short-chain fructooligosaccharides (FOS). Finally, water can also act as nucleophile acceptor of the fructosyl-levansucrase intermediate releasing free fructose (hydrolysis). The balance between the three reactions strongly depends on the nature of the enzyme and on the experimental conditions [32].

The levansucrase from Zymomonas mobilis employed in this work presented a major band of approximately $45 \mathrm{kDa}$ in SDS-PAGE gels, in accordance with previous reports [33]. The optimal conditions of temperature and $\mathrm{pH}$ were analyzed by the DNS method with $100 \mathrm{~g} / \mathrm{L}$ sucrose as substrate. This colorimetric method is not able to discriminate between the three activities of the enzyme, as it only measures the release of reducing sugars. However, the DNS method was useful to establish initial conditions. Levansucrase displayed its maximum activity at $40^{\circ} \mathrm{C}$ and $\mathrm{pH} 5.4$ (Figs. 1A and 1B, respectively), which was in agreement with previous studies with this enzyme [34].

We analyzed the synthesis of levan by size exclusion chromatography (SEC-HPLC) under different sucrose concentrations (100 g/L, Fig. 2A; 600 g/L, Fig. 2C) and temperatures $\left(4\right.$ and $40^{\circ} \mathrm{C}$ ) at $\mathrm{pH} 5.4$ using $5 \mathrm{U} / \mathrm{mL}$ of levansucrase. SEC analysis showed that the highest yield of levan was obtained at $4^{\circ} \mathrm{C}$ and $100 \mathrm{~g} / \mathrm{L}$ sucrose (Fig. 2A). The synthesized levan presented the same retention time than the commercial levan from Zymomonas mobilis used as standard (data not shown). Based on the chromatographic mobility, the molecular weight (MW) of the formed levan was greater than that of the dextran of higher MW used as standard $(144 \mathrm{kDa})$. In this context, the MW of the levan synthesized by other bacterial levansucrases, e.g. from Bacillus subtilis, is at least of 2,000 $\mathrm{kDa}$ (reaching values of 100 million $\mathrm{Da}$ ) with a minimum of 10,000 fructosyl moieties [20]. At both sucrose concentrations, the levan obtained at $40^{\circ} \mathrm{C}$ showed a slightly higher retention time than its homologous formed at $4^{\circ} \mathrm{C}$, which indicated a lower degree of polymerization at higher temperature. At $4^{\circ} \mathrm{C}$ and $600 \mathrm{~g} / \mathrm{L}$ sucrose, the levan peak displayed a shoulder that could be related with the presence of a component of lower molecular weight in the biopolymer fraction (Fig. 2C). This result was in accordance with Vigants et al. [22], who described that levansucrase is more likely to form longer polysaccharides at lower temperatures. We also analyzed levan formation at $25^{\circ} \mathrm{C}$ and the amount of polysaccharide was in between that obtained at $4^{\circ} \mathrm{C}$ and $40^{\circ} \mathrm{C}$ (data not shown).

The reaction mixtures were also analyzed by HPAEC-PAD to visualize the formation of FOS and the hydrolysis of sucrose under the same conditions (Figs. 2B and 2D for 100 $\mathrm{g} / \mathrm{L}$ and $600 \mathrm{~g} / \mathrm{L}$ respectively). At $100 \mathrm{~g} / \mathrm{L}$, the low-molecular-weight fraction was formed basically by glucose (which is a by-product of both transfructosylation and hydrolysis reactions), fructose (released only in the hydrolysis reaction) and the remaining sucrose. Several FOS appeared in the chromatogram, but their concentration was significantly lower than that of the mono- and disaccharides. However, at $600 \mathrm{~g} / \mathrm{L}$ of sucrose, the FOS concentration substantially increased (Fig. 2D). A feasible explanation is that a competition is established between the synthesis of short FOS and the formation of highmolecular-weight levan. At high sucrose concentrations, the role of sucrose as acceptor of 
the fructosyl-enzyme intermediate is favoured and thus short-chain oligosaccharides are synthesized. At lower sucrose concentrations, the growing levan chain has less competence to accept the fructosyl moieties of the fructosyl-enzyme intermediate. Similar results have been obtained with related enzymes such as dextransucrases in the competitive formation of glucooligosaccharides and dextran $[35,36]$.

Fig. 2D clearly shows that as higher the temperature is increased the formation of FOS. The differences in FOS formation between the two temperatures when $100 \mathrm{~g} / \mathrm{L}$ sucrose was used as substrate were not so evident compared with the experiments carried out with $600 \mathrm{~g} / \mathrm{L}$ sucrose.

We measured the concentrations of glucose, fructose and sucrose after $2 \mathrm{~h}$ reaction in order to analyze the transglycosylation to hydrolysis ratio under the different experimental conditions. Hydrolytic activity $(\mathrm{H})$ was quantified by the concentration of free fructose. Transfructosylating activity (T) was calculated by the difference between the concentration of free glucose and fructose. The transfructosylation to hydrolysis $(\mathrm{T} / \mathrm{H})$ ratio was calculated dividing both activities. Table 1 summarizes the T/H values and the percentage of sucrose consumed after $2 \mathrm{~h}$ reaction. Sucrose conversion was notably higher at $40^{\circ} \mathrm{C}$, as expected from the optimum activity this enzyme (Fig. 1A). Interestingly, the T/H ratio was between 1.8- and 3-fold higher at $4^{\circ} \mathrm{C}$ compared with $40^{\circ} \mathrm{C}$, which was in accordance with previous reports [34,37]. In addition, the $\mathrm{T} / \mathrm{H}$ ratio was higher when sucrose concentration increased, because this disaccharide competes with water for the fructosyl-enzyme intermediate.

\subsection{Analysis of the fructooligosaccharide fraction by HPAEC-PAD}

We showed above that, out of the conditions assayed, the highest fructooligosaccharides yield was obtained at $600 \mathrm{~g} / \mathrm{L}$ sucrose and $40^{\circ} \mathrm{C}$. The profile of synthesized FOS under such conditions was studied in detail. The reaction mixtures after $50 \mathrm{~h}$ were first analyzed by HPAEC-PAD with a CarboPack PA200 column, which exhibits a good resolution in a broad range of polymerization degree (up to approx. 60). Commercial inulin was used as a standard (Fig. 3A, grey chromatogram); this polysaccharide showed major $\mathrm{GF}_{\mathrm{n}}$ peaks $[n$ fructoses with $\beta(2 \rightarrow 1)$ bonds and a terminal glucose] and small $F_{n}$ peaks [ $n$ fructoses with $\beta(2 \rightarrow 1)$ bonds]. Fig. 3A shows that, in the reaction of levansucrase with sucrose, peaks equivalent in size up to the $\mathrm{GF}_{20}$ of inulin (approx. $3.78 \mathrm{kDa}$ ) can be visualized, which illustrates how the levan chain gradually grows. However, the main products obtained under these conditions were small carbohydrates, basically di-, tri- and tetrasaccharides.

In order to analyze the composition of the major FOS in the mixture, we analyzed the same sample with a CarboPack PA1 column (Fig. 3B) that gives a better resolution in the low MW region. With the use of standards, several FOS were identified: 1-kestose (peak 5), blastose (6), 6-kestose (8), neokestose (10), nystose (12), neonystose (14) and ${ }^{1} \mathrm{~F}$ fructosylnystose (18). Several products not coeluting with any of the available standards could not be identified.

Fig. 4A illustrates the time course of the formation of the main acceptor products (the three kestoses and the tetrasaccharide nystose). At the beginning of the reaction the most abundant oligosaccharide was 6-kestose, reaching a maximum at $6 \mathrm{~h}$. Afterwards the concentration of 6-kestose diminished as it was used as scaffold to elongate the levan 
chain. In contrast, 1-kestose accumulated progressively. It is also noteworthy the presence of blastose [Fru- $\beta(2 \rightarrow 6)$-Glc] in the reaction mixtures. This sucrose isomer was previously reported in the reaction of sucrose with the levansucrase from B. megaterium; the authors demonstrated that it was formed by the hydrolysis of the synthesized neokestose [24]. In our work, blastose accumulated whereas neokestose concentration decreased (Fig. 4A) confirming such hypothesis, although it was not possible to rule out that blastose could be synthesized by the acceptor reaction with glucose.

Production of known FOS by levansucrase reached its maximum when $85 \%$ of sucrose was consumed ( $21 \mathrm{~h}$ of reaction). At this point of the reaction (Fig. $4 \mathbf{B}$ ) the mixture was made up of $31 \%$ glucose, $14 \%$ fructose, $15 \%$ sucrose, $15 \%$ of quantified FOS (for which standards were available) and $25 \%$ of unknown products (including the small amount of levan, Fig. 2C). The concentration of unknown products was estimated as the difference between initial sucrose concentration and the sum of known products.

\subsection{Identification of a tetrasaccharide synthesized by levansucrase}

We isolated by semipreparative HPLC peak 13 in Fig. 3B, which was one of the unknown FOS obtained at higher concentration with levansucrase. The compound was purified and characterized by mass spectrometry and NMR. Mass spectrometry showed that it was a tetrasaccharide ( $\mathrm{MW}=666 \mathrm{~g} / \mathrm{mol}$, supplementary material). The $1 \mathrm{D}$ and $2 \mathrm{D}$ ${ }^{1} \mathrm{H}$ NMR spectra displayed one anomeric signal, arising from the glucose residue and several signal group patterns, recognizable as fructose moieties. From the analysis of the signals present in the COSY, NOESY, HSQC, HSQC-TOCSY and HMBC spectra, the full assignment of the ${ }^{1} \mathrm{H}$ and ${ }^{13} \mathrm{C}$ resonance signals belonging to the different residues was achieved (Fig. 5). In particular, TOCSY and HSQC-TOCSY spectra permitted to assign the spin systems, while the connectivity was unravelled from key cross peaks in the NOESY and HMBC spectra. The glycosylation positions in the fructosyl (Fru) residues were determined from the existence of key cross peaks between the H6 at Fru(F1) residue and the quaternary carbon $\mathrm{C} 2$ at $\mathrm{Fru}(\mathrm{F} 2)$ in the HMBC spectrum, as well as the equivalent cross peak between the $\mathrm{H} 6$ at $\mathrm{Fru}(\mathrm{F} 2)$ residue and the quaternary carbon $\mathrm{C} 2$ at Fru(F3). Moreover, the connectivity between the Glc and Fru (F1) residues was determined from the existence of a cross peak between the glucose $\mathrm{H} 1$ and the quaternary carbon $\mathrm{C} 2$ from fructose (F1) in the same HMBC spectrum. Thus, the NMR data permitted to unambiguously identify peak 13 as 6,6 -nystose $[$ Fru- $\beta(2 \rightarrow 6)$-Fru- $\beta(2 \rightarrow 6)$-Fru- $\beta(2 \rightarrow 1)$ $\alpha \mathrm{Glc}]$, a member of the levan-type FOS.

Fig. 6 summarizes the different steps involved in the reaction of sucrose with levansucrase from $Z$. mobilis. Once the fructosyl-enzyme intermediate is formed, different acceptors can participate in the process. The three major trisaccharides (1-kestose, neokestose and 6-kestose), which are formed when sucrose acts as acceptor, give rise to

further elongation products. However, the homologous series of 6-kestose (whose next member is the identified 6,6-nystose) is the most determinant as it gives rise to the levan biopolymer. The levan may also contain $\beta(2 \rightarrow 1)$ branches; the model compound of this group is the tetrasaccharide bifurcose [38], which probably corresponds to any of the unidentified peaks in the chromatogram (Fig. 3B). The released glucose can also act as acceptor yielding blastose, although this disaccharide can be also generated by hydrolysis of neokestose. The fructose formed by the hydrolytic activity of levansucrase may also act 
as acceptor, producing fructosyl oligomers (levanbiose, levantriose, etc.) that have been also detected in reactions catalyzed by levansucrase [39].

\section{CONCLUSIONS}

Our experiments confirm that the temperature and substrate concentration strongly influence the selectivity of levansucrase. This effect can be used to shift the levansucrase activity towards the production of FOS or levan. Levansucrase synthesizes a mixture of ${ }^{1} \mathrm{~F}$ FOS, ${ }^{6} \mathrm{~F}-\mathrm{FOS}$ and ${ }^{6} \mathrm{G}$-FOS, which could be of interest for the prebiotic industry due to possible synergistic effects between the different carbohydrates. The first member of the ${ }^{6} \mathrm{~F}$-family (6-kestose) acts as building block to elongate the levan chain through $\beta(2 \rightarrow 6)$ linkages between the fructosyl moieties.

\section{ACKNOWLEDGMENTS}

This work was supported by a grant from the Spanish Ministry of Economy and Competitiveness (BIO2013-48779-C4-1-R). We thank the support of COST-Action CM1303 on Systems Biocatalysts. We thank Amano Enzyme Inc. (Japan) for the kind donation of the levansucrase. We thank Beneo Iberica for the generous supply of an inulin sample (Raftiline). P. S-M. thanks the Spanish Ministry of Education for FPU Grant. 


\section{REFERENCE LIST}

[1] B. Henrissat, G.J. Davies, Plant Physiol. 124 (2000) 1515-1519.

[2] Y.W. Han, Adv. Appl. Microbiol. 35 (1990) 171-194.

[3] K.H. Kim, C.B. Chung, Y.H. Kim, K.S. Kim, C.S. Han, C.H. Kim, J. Cosmet. Sci. 56 (2005) 395-406.

[4] B.Y. Byun, S.J. Lee, J.H. Mah, Int. J. Food Sci. Technol. 49 (2014) 238-245.

[5] M. Bekers, M. Marauska, A. Grube, D. Karklina, M. Duma, Acta Aliment. 33 (2004) 31-37.

[6] M.Y. Huang, C.F. Lee, S.T. Ho, K.J. Lin, C.L. Pan, J. Pure Appl. Microbiol. 7 (2013) 1585-1599.

[7] N.H. Park, H.J. Choi, D.K. Oh, Biotechnol. Lett. 27 (2005) 495-497.

[8] E.W. Lyness, H.W. Doelle, Biotechnol. Lett. 5 (1983) 345-350.

[9] H.E. Park, N.H. Park, M.J. Kim, T.H. Lee, H.G. Lee, J.Y. Yang, J. Cha, Enz. Microb. Technol. 32 (2003) 820-827.

[10] F. Tian, L. Inthanavong, S. Karboune, Biosci. Biotech. Bioch. 75 (2011) 1929-1938.

[11] T. Zhang, R. Li, H. Qian, W. Mu, M. Miao, B. Jiang, Carbohydr. Polym. 101 (2014) 975-981.

[12] A. Poli, H. Kazak, B. Gürleyendag, G. Tommonaro, G. Pieretti, E.T. Öner, B. Nicolaus, Carbohydr. Polym. 78 (2009) 651-657.

[13] S. Silbir, S. Dagbagli, S. Yegin, T. Baysal, Y. Goksungur, Carbohydr. Polym. 99 (2014) 454-461.

[14] I.L. Shih, L.D. Chen, J.Y. Wu, Carbohydr. Polym. 82 (2010) 111-117.

[15] C.J. Chiang, J.Y. Wang, P.T. Chen, Y.P. Chao, Appl. Microbiol. Biotechnol. 82 (2009) 445-451.

[16] K.H. Jang, K.B. Song, B.S. Park, C.H. Kim, B.H. Chung, R.W. Choue, K.S. Lee, C. Lee, U.H. Chun, S.K. Rhee, Process Biochem. 37 (2001) 339-343.

[17] M. Bekers, J. Laukevics, D. Upite, E. Kaminska, A. Vigants, U. Viesturs, L. Pankova, A. Danilevics, Process Biochem. 38 (2002) 701-706.

[18] M. Sabater-Molina, E. Larque, F. Torrella, S. Zamora, J. Physiol. Biochem. 65 (2009) 315-328.

[19] K.H. Jang, E.J. Ryu, B.S. Park, K.B. Song, S.A. Kang, C.H. Kim, T.B. Uhm, Y.I. Park, S.K. Rhee, J. Agric. Food Chem. 51 (2003) 2632-2636.

[20] T. Tanaka, S. Oi, T. Yamamoto, J. Biochem. 87 (1980) 297-303. 
[21] H. Yanase, M. Iwata, K. Kita, N. Kato, K. Tonomura, J. Ferment. Bioeng. 79 (1995) 367-369.

[22] A. Vigants, D. Upite, R. Scherbaka, J. Lukjanenko, R. Ionina, Folia Microbiol. 58 (2013) 75-80.

[23] D. Goldman, N. Lavid, A. Schwartz, G. Shoham, D. Danino, Y. Shoham, J. Biol. Chem. 283 (2008) 32209-32217.

[24] A. Homann, R. Biedendieck, S. Götze, D. Jahn, J. Seibel, Biochem. J. 407 (2007) 189-198.

[25] F. Tian, S. Karboune, A. Hill, Innov. Food Sci. Emerg. Technol. 22 (2014) 230-238.

[26] F. Tian, M. Khodadadi, S. Karboune, J. Mol. Catal. B-Enzym. 109 (2014) 85-93.

[27] M. Alvaro-Benito, M. de Abreu, L. Fernandez-Arrojo, F.J. Plou, J. Jimenez-Barbero, A. Ballesteros, J. Polaina, M. Fernandez-Lobato, J. Biotechnol. 132 (2007) 75-81.

[28] D. Linde, B. Rodriguez-Colinas, M. Estevez, A. Poveda, F.J. Plou, M. FernandezLobato, Bioresour. Technol. 109 (2012) 123-130.

[29] I. Ghazi, L. Fernandez-Arrojo, H. Garcia-Arellano, M. Ferrer, A. Ballesteros, F.J. Plou, J. Biotechnol. 128 (2007) 204-211.

[30] H.T.S. Britton, R.A. Robinson, J. Chem. Soc. (1931) 1456-1462.

[31] C. Olvera, S. Centeno-Leija, P. Ruiz-Leyva, A. Lopez-Munguia, Appl. Environ. Microbiol. 78 (2012) 1820-1825.

[32] F. Tian, S. Karboune, J. Mol. Catal. B-Enzym. 82 (2012) 71-79.

[33] A. Vigants, H.G. Hicke, S.P. Marx, Curr. Microbiol. 42 (2001) 415-418.

[34] H. Yanase, M. Iwata, R. Nakahigashi, K. Kita, N. Kato, and K. Tonomura, Biosci. Biotech. Bioch. 56 (1992) 1335-1337.

[35] M. Alcalde, F.J. Plou, A. Gomez de Segura, M. Remaud-Simeon, R.M. Willemot, P. Monsan, A. Ballesteros, Biotechnol. Tech. 13 (1999) 749-755.

[36] A. Gomez de Segura, M. Alcalde, F.J. Plou, M. Remaud-Simeon, P. Monsan, A. Ballesteros, Biocatal. Biotransfor. 21 (2003) 325-331.

[37] K.H. Jang, K.B. Song, C.H. Kim, B.H. Chung, S.A. Kang, U.H. Chun, R.W. Choue, S.K. Rhee, Biotechnol. Lett. 23 (2001) 339-344.

[38] M.L. Velazquez-Hernandez, V.M. Baizabal-Aguirre, A. Bravo-Patiño, M. CajeroJuarez, M.P. Chavez-Moctezuma, J.J. Valdez-Alarcon, J. Appl. Microbiol. 106 (2009) 1763-1778.

[39] T. Tanaka, S. Yamamoto, S. Oi, T. Yamamoto, J. Biochem. 90 (1981) 521-526. 


\section{Figure legends}

Fig. 1. (A) Temperature-activity and (B) pH-activity profiles of levansucrase from $Z$. mobilis. The relative activity refers to the maximum activity at the optimal conditions of temperature and $\mathrm{pH}$, respectively.

Fig. 2. (A) SEC chromatogram and (B) HPAEC-PAD chromatogram of the reaction mixture after $24 \mathrm{~h}$ incubation of levansucrase with $100 \mathrm{~g} / \mathrm{L}$ sucrose at $4^{\circ} \mathrm{C}$ (thick line) and $40^{\circ} \mathrm{C}$ (grey line). (C) SEC chromatogram and (D) HPAEC-PAD chromatogram of the reaction after $24 \mathrm{~h}$ incubation of levansucrase with $600 \mathrm{~g} / \mathrm{L}$ sucrose at $4^{\circ} \mathrm{C}$ and $40^{\circ} \mathrm{C}$. Glc: glucose; Fru: fructose; Suc: sucrose; FOS: fructooligosaccharides.

Fig. 3. (A) HPAEC-PAD chromatogram with CarboPack PA200 column (thick line) of FOS profile after $50 \mathrm{~h}$ reaction of levansucrase with $600 \mathrm{~g} / \mathrm{L}$ sucrose at $40^{\circ} \mathrm{C}$. In grey line, chromatogram of inulin standard. GFn: $n$ fructoses with $\beta(2 \rightarrow 1)$ linkages and a terminal glucose. (B) HPAEC-PAD chromatogram with CarboPack PA1 column of FOS synthesized by levansucrase with $600 \mathrm{~g} / \mathrm{L}$ sucrose after $18 \mathrm{~h}$ reaction at $40^{\circ} \mathrm{C}$. Peak identification: 1, glucose; $\mathbf{2}$, fructose; $\mathbf{3}$, sucrose; 5, 1-kestose; $\mathbf{6}$, blastose; $\mathbf{8}$, 6-kestose; 10, neokestose; 12, nystose; 13, isolated tetrasaccharide; 14 , neonystose; $18,{ }^{1} \mathrm{~F}$ fructosylnystose.

Fig. 4. Reaction of Z. mobilis levansucrase with $600 \mathrm{~g} / \mathrm{L}$ sucrose at $\mathrm{pH} 5.4$ and $40^{\circ} \mathrm{C}$. (A) Time course of the formation of the main FOS (left axis) and sucrose depletion (right axis). (B) Composition of the reaction mixture (in weight percentage) at the point of maximum FOS concentration $(21 \mathrm{~h})$.

Fig. 5. 2D-NMR DEPT-HSQC spectra of 6 ,6-nystose [Fru- $\beta(2 \rightarrow 6)$-Fru- $\beta(2 \rightarrow 6)$-Fru$\beta(2 \rightarrow 1)-\alpha \mathrm{Glc}]$. The signals are assigned and labelled. The key points for identifications are also shown.

Fig. 6. Scheme of the formation of FOS and levan by levansucrase from Z. mobilis. Fructosyl-LEV refers to the fructosyl-enzyme intermediate. 
Fig. 1
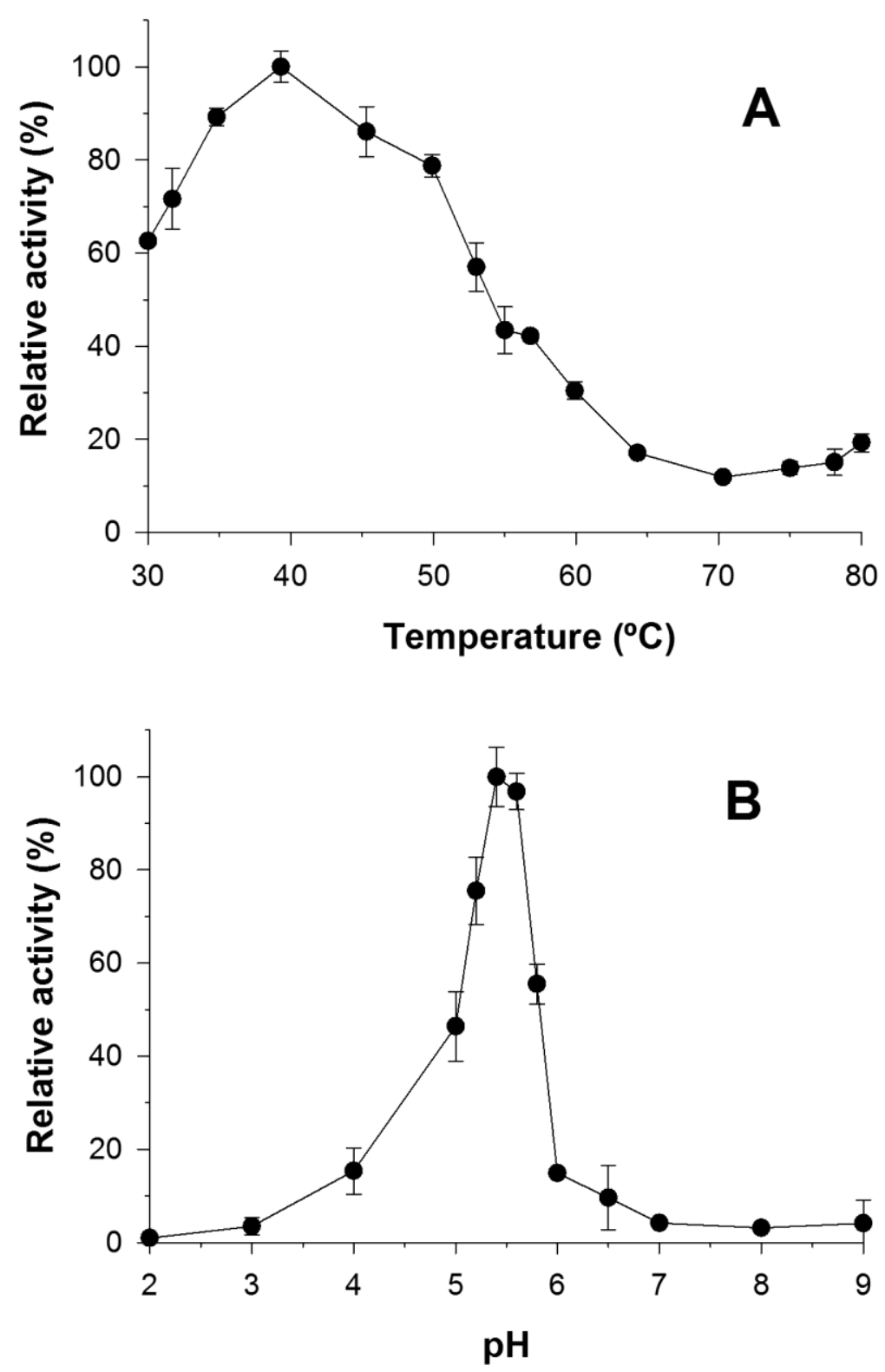
Fig. 2
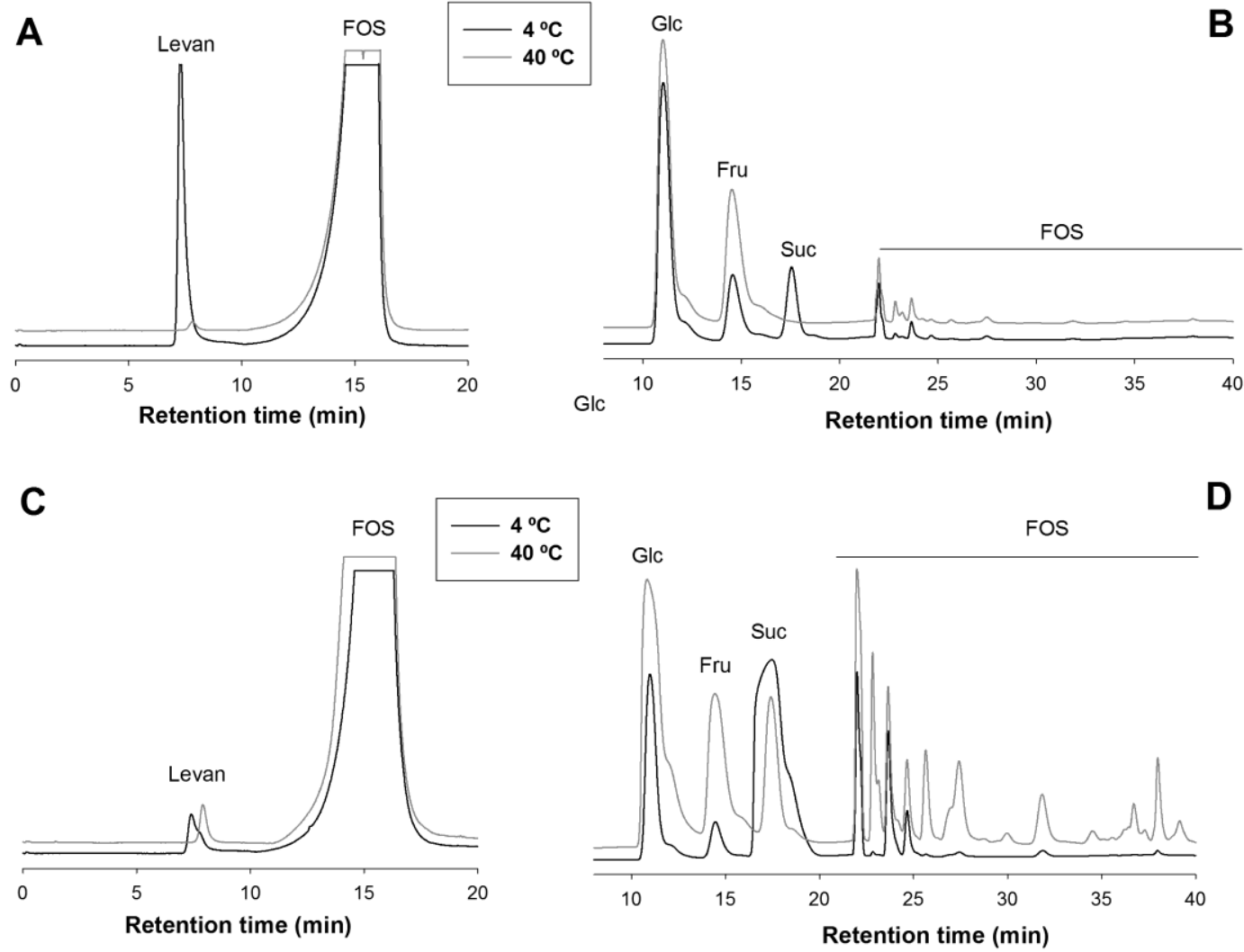
Fig. 3
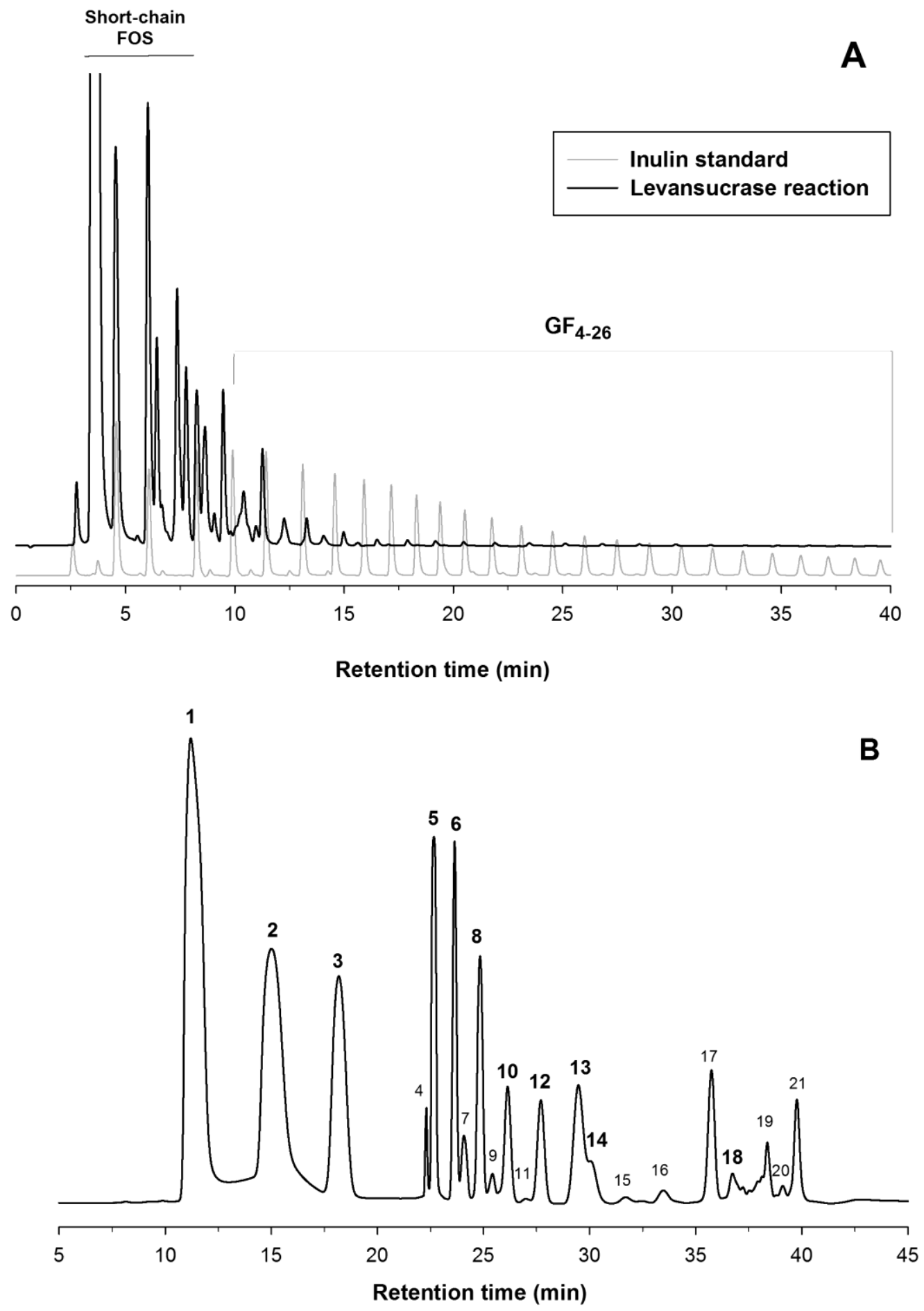
Fig. 4
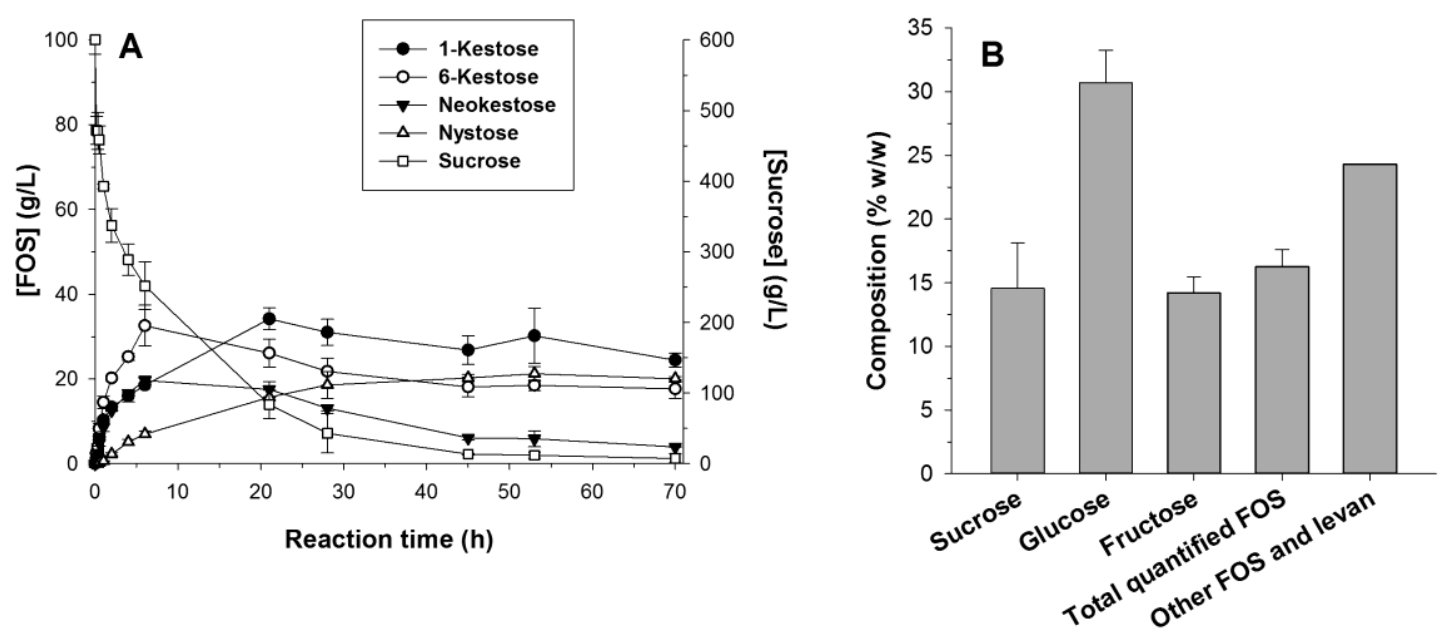
Fig. 5

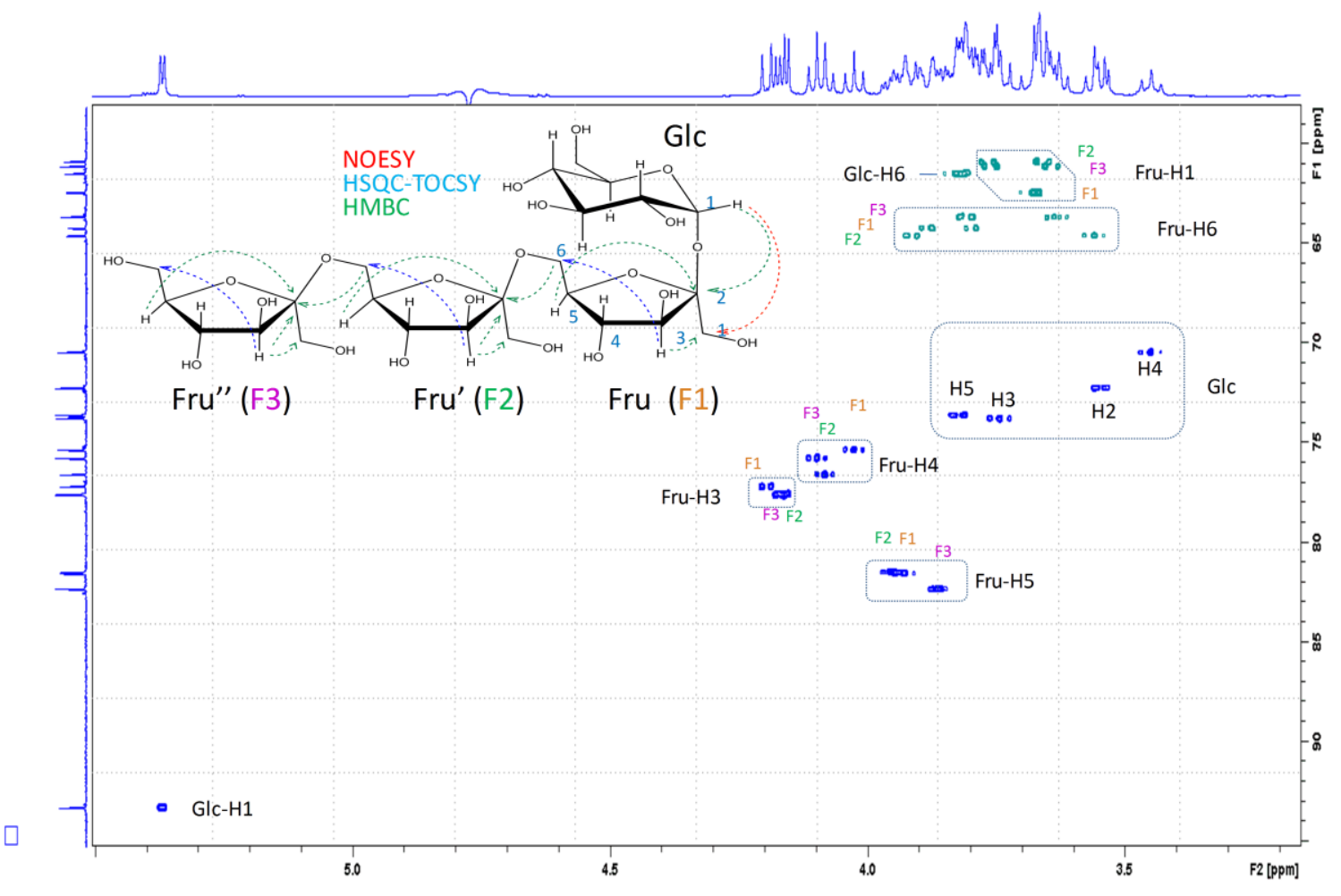


Fig. 6

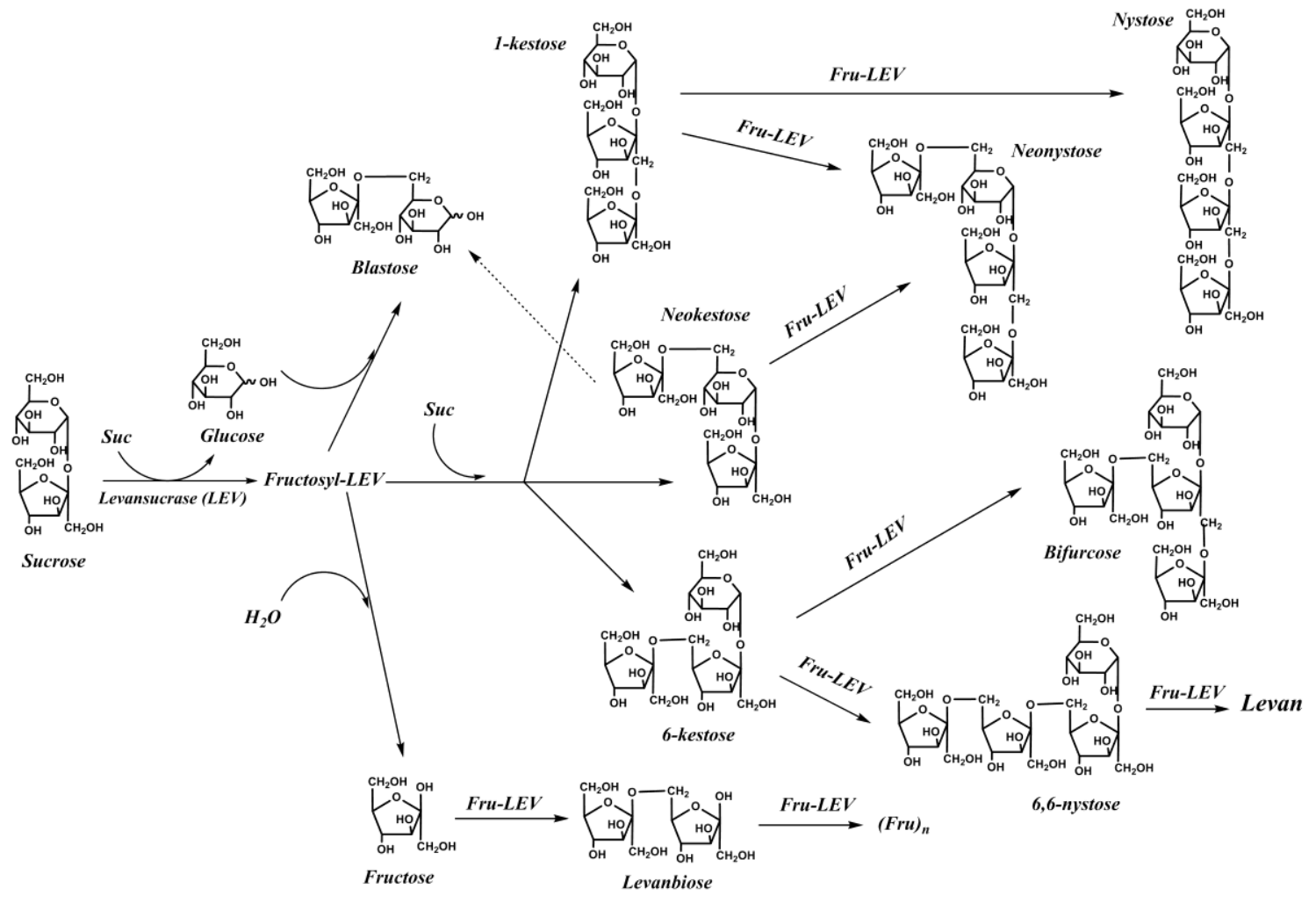

